\title{
FILOSOFÍA Y SOCIOLOGÍA DE LA EDUCACIÓN EN CLAVE DE RECONOCIMIENTO
}

\author{
Philosophy and Sociology of Education in key of Recognition
}

Ángel Guillermo Gómez Navarro*

Recepción: 23-10-2018

Aceptación: 02-11-2018

\begin{abstract}
RESUMEN
El presente ensayo reflexiona sobre las exigencias educativas de la formación de las identidades y del reconocimiento de las diferencias culturales en nuestra sociedad democrática. Para ello se somete a revisión crítica la articulación de las competencias que subyacen a los dos modelos que coexisten en las instituciones educativas de nuestro entorno y se toma posición por un modelo educativo que incluye las humanidades teniendo como referente teórico las ideas filosóficas de Charles Taylor.
\end{abstract}

\section{Palabras clave}

Modernidad, Acción comunicativa, Habermas, Modernidad peruana, Racionalidad.

\begin{abstract}
This essay reflects on the educational demands of the construction of identities and the recognition of cultural differences in our democratic society. To this end, the articulation of the competences underlying the two models that coexist within our educational institutions is subjected to a critical review and a position is taken in favor of an educational model that includes the humanities, taking as theoretical referent the philosophical ideas of Charles Taylor.
\end{abstract}

\section{Keywords:}

Recognition, educational models, humanities, competences, identity.

* Docente Principal de la Universidad Femenina Sagrado Corazón (UNIFE): agomez@unife.edu.pe 


\section{INTRODUCCIÓN}

El presente ensayo tiene como propósito establecer una revisión crítica sobre las formas de promover las relaciones sociales de reconocimiento mutuo entre estudiantes de educación básica y pregrado, especialmente en lo referido a las identidades individuales y las diferencias culturales. Se trata de analizar los modelos educativos basados en las humanidades y otros en el enfoque tecnológico, los cuales pugnan entre las diversas instituciones escolares y universitarias, públicas y privadas.

Estos modelos educativos tienen no sólo una manera propia de concebir la calidad de la educación en general y de redefinir el rol de las humanidades, las ciencias sociales y las ciencias naturales básicas, sino también de promover la formación de la identidad y autonomía de los estudiantes según las mallas curriculares que orientan la enseñanza formativa e investigativa de los futuros profesionales y ciudadanos del país, y en un contexto histórico de tensión entre el enfoque humanístico y el proceso de mercantilización de la educación.

Así, el modelo educativo inspirado en las humanidades defendido por la UNESCO (1998), concibe a la educación como un bien público o derecho humano que los Estados deben salvaguardar, y promueve un conjunto de saberes o competencias que apuntan a la formación para la ciudadanía responsable y la participación democrática. En efecto, se trata de los cuatro saberes de la educación que Delors (1996), clasifica como: saber (obtener conocimientos y pensamiento crítico), saber hacer (aplicar los conocimientos para la resolución de problemas), saber ser (formarse una identidad, crecer como persona y desarrollar las libertades) y saber convivir (respetar las diferencias personales y culturales y velar por el bien común), los cuales buscan asegurar no sólo la producción y reproducción de los conocimientos relevantes, sino también la identidad y la tolerancia para una mejor convivencia social.

Por su parte, el modelo tecnocrático, promovido por la Organización Mundial del Comercio (OMC, 1995), concibe a la educación como un bien comercial o servicio (mercancía), a ser regulada por los Estados en el marco del Acuerdo General sobre Comercio de Servicios (López Segrera 2006), y asume el ideal empresarial que excluye los valores cívicos, y hace suyo el enfoque por competencias subrayando sólo la búsqueda de la competitividad, la eficacia, la eficiencia, la utilidad y la rentabilidad, y en donde la formación de la identidad y la autonomía son vistas sólo en función de lograr estatus, éxito o diferenciación económica

Es este último modelo el que vienen promoviendo los Estados locales y globales, y que Martha Nussbaum (2010), cuestiona en los siguientes términos: "Sedientos de dinero los Estados nacionales y sus sistemas de educación están descartando sin advertirlo ciertas aptitudes que son necesarias para mantener viva a la democracia. Si esta tendencia se prolonga, las naciones de todo el mundo en breve producirán generaciones enteras de máquinas utilitarias, en lugar de ciudadanos cabales con la capacidad de pensar por sí mismos, poseer una mirada crítica sobre las tradiciones y comprender la importancia de los logros y los sufrimientos ajenos" (Nussbaum 2010 Introducción).

El cuestionamiento de Nussbaum se extiende también al caso peruano que parece haber optado por legitimar el 
modelo tecnocrático como una forma de desreconocimiento y promoción de una identidad igualitaria de los destinatarios de la educación según sólo los 'valores' empresariales. En efecto, la privatización de la educación, iniciada en 1996, buscó que todos puedan recibir educación, pero sin garantizar las debidas exigencias de calidad educativa. Así aparecieron los colegios y universidades empresariales "con fines de lucro" que, a diferencia de las otras instituciones tradicionales, denominadas "sin fines de lucro", han terminado definiendo modelos educativos que relega la importancia para educar en la capacidad de saber ser y saber convivir, es decir, de formar para el reconocimiento entre los actores sociales. En efecto, en sus planes de estudios han sido excluidos o minimizados tanto las humanidades (Filosofía, Literatura, etc.) como las ciencias sociales y; por otro lado, se considera sólo a las asignaturas que aseguran las competencias específicas de las respectivas carreras profesionales según la demanda de la empresa y el mercado local y global. Es decir, se excluyen aquellas asignaturas que buscan promover las condiciones para reconocer nuestras identidades y diferencias culturales, es decir, las competencias del pensamiento crítico-socrático y el significado y sentido de los "valores socioculturales" que exigen las sociedades democráticas (Nussbaum 2005). Incluso la tendencia actual entre las universidades "sin fines de lucro" consiste en reducir horas y quitarle obligatoriedad a las asignaturas de humanidades y ciencias sociales con el argumento de que numerosas de estas no actualizan sus contenidos ni renuevan sus estrategias pedagógicas. Sin embargo, independientemente de la predisposición o no de los estudiantes, así como de los resultados que se puedan esperar, dicha tendencia muestra la subordinación de la universidad a las exigencias de la empresa y el mercado y no a las de la sociedad y sus valores cívicos. De este modo, se pierde de vista la misión de orientar correctamente la labor formativa a favor del reconocimiento mutuo y se corre el riesgo de que esta quede sometida solo a los intereses de los grupos de poder político y económico.

\section{EDUCACIÓN E IDENTIDAD}

Una óptima educación puede potenciar el nexo existente entre reconocimiento e identidad, ya que la identidad se construye también por el reconocimiento o no de los otros; de ahí que no promover y orientar equivocadamente el reconocimiento podría afectar seriamente la autoconcepción del individuo. Esta idea inspirada en la obra del filósofo canadiense Charles Taylor "El multiculturalismo y la política del reconocimiento" (2009) se condice con el hecho de que "el falso reconocimiento o la falta de reconocimiento pueden causar daño, pueden ser una forma de opresión que subyugue a alguien en un modo de ser falso, deformado y reducido". En realidad, el reconocimiento es una necesidad humana vital, clave para la formación de la identidad del sujeto, de modo que no puede quedar desvinculado del mundo y de su temporalidad, pues se afectaría la estrecha relación que existe entre reconocimiento e identidad.

Por consiguiente, un modelo educativo que promueva las condiciones subjetivas y objetivas para un auténtico reconocimiento deberá ser dialógico, no monológico, ya que para Taylor (2009), el rasgo decisivo de la vida humana es su carácter fundamentalmente dialógico. Siempre definimos nuestra identidad en diálogo con las cosas que nuestros otros significantes desean ver en nosotros, y a veces en lucha con ellas. De este modo, se puede 
predecir que una educación solamente tecnológica seguirá el ideal monológico porque desmerece lo dialógico en la vida humana y no considera la formación de la identidad que depende casi siempre de las relaciones dialógicas con los otros.

Por otro lado, el mismo Taylor (2009) sostiene que el ser humano es un ser eminentemente hermenéutico, ya que "nuestra comprensión de nosotros mismos es constitutiva de lo que nosotros somos". Por tanto, la pregunta por nosotros mismos, como quiénes somos y de dónde venimos, es una forma de forjar la propia identidad, es una forma por la que el ser humano se interpreta a sí mismo: "Nos convertimos en agentes humanos plenos, capaces de comprendernos a nosotros mismos y por tanto de definir nuestra identidad, a través de nuestra adquisición de ricos lenguajes expresivos humanos".

En este sentido, las asignaturas de filosofía y literatura, propia de las humanidades, permiten el desarrollo de esa capacidad de expresarnos y de realizarnos en interacción con los otros, posibilitan lenguajes diferentes que nos enriquecen y construyen como personas con una identidad propia.

Se trata de un lenguaje dialógico que posibilita la autorrealización de aquella identidad que potencialmente se puede desarrollar, sin que esto signifique que sean los otros los que definan o determinen nuestra identidad. Pero, como bien subraya nuestro filósofo, una identidad no se forja monológicamente o desvinculada de los demás, ya que el reconocimiento es relevante para nuestra propia identidad.

La idea que Taylor (2009) considera como muy relevante es cómo una autoconciencia, en cuanto individuo, llega a alcanzar su identidad dentro de una comunidad de otros individuos. En realidad, la dignidad e identidad de cada individuo deben ser reconocidas universalmente por los otros y por la comunidad en las sociedades democráticas. Sin embargo, la identidad individual moderna no goza de un reconocimiento a priori. Debe ganarse por medio del intercambio, aunque el intento puede fracasar. De ahí la importancia de pedagogías dialógicas que son inherentes a las humanidades y que deberían ser promovidas por las diversas instituciones educativas públicas y privadas, y de los diversos niveles formativos: primario, secundario y superior.

Por las consideraciones taylorianas antes mencionadas legitimamos el modelo educativo basado en las humanidades bajo ciertas condiciones, como la renovación constante de sus contenidos, métodos y estrategias pedagógicas, según la lógica de una educación socrática defendida por Nussbaum en su texto "El cultivo de la humanidad" (2005), y como una forma efectiva de contribuir a forjar una identidad en el contexto de una comunidad culturalmente diferenciada. En realidad, el desafío consiste en asumir un enfoque integral de la educación que no excluya las competencias propias las ciencias naturales y tecnológicas, sino que incluya aquellas que permitan a los estudiantes desarrollar la capacidad dialógica y aprender a plantear interrogantes sobre el significado y sentido de una sociedad justa y libre, capacitándolos para la participación ciudadana y la democracia.

Al respecto, Martiniano Román (2006), defendiendo el enfoque de competencias en la educación, puntualiza que en nuestras sociedades es necesario desarrollar un pensamiento sistémico o complejo, asociado a métodos y 
procesos cognitivos, los cuales deben estar relacionados, a su vez, con los valores institucionales y sociales, como un componente relevante y básico de la nueva cultura en la sociedad del conocimiento. Asimismo, Edgar Morin, en "Los siete saberes necesarios para la educación del futuro" (1999), sostiene que hay que tener aptitud para saber contextualizar los saberes e integrarlos dentro de sus conjuntos. Más aún, señala que el conocimiento progresa principalmente, no por sofisticación, formalización o abstracción, sino por la capacidad de contextualizar y globalizar.

\section{FILOSOFÍA Y ANTROPOLOGÍA DE LOS MODELOS EDUCATIVOS}

El panorama escolar y universitario parece no estar claro en relación a la formación de un correcto reconocimiento en las relaciones sociales y, por lo mismo, una óptima formación de la identidad de los protagonistas. Sin embargo, es necesario identificar qué tipo de interpretación filosófica y antropológica subyace en cada uno de los modelos educativos que pugnan en las instituciones educativas vigentes, así como el tipo de sociedad que legitiman.

El modelo tecnológico o tecnocrático defiende una educación basada en desarrollar sólo aquellas competencias útiles para desenvolverse con éxito en el mercado y parece tener la debida legitimación de los estudiantes; pero esto contrasta con nuestra posición a favor de una educación comprometida con la formación de la identidad, autonomía y reconocimiento de las diferencias culturales. Lo que el paradigma de las humanidades considera inaceptable del modelo tecnológico positivista es la promoción de una identidad individualista, mercantilista y consumista, ya que sólo mira a beneficiar el árbol del mercado y no al bosque de la sociedad, y por lo mismo forma sólo sujetos atomizados e insolidarios por el que se reproducen las exclusiones y desigualdades.

Sin embargo, una visión educativa integral de las competencias podría ser considerada como una condición de posibilidad para el reconocimiento de las diferencias en la vida escolar y universitaria, pues todos deben desarrollar sus capacidades o expandir sus libertades como una exigencia universal en los protagonistas de la educación que demandan calidad total.

Desde esta perspectiva, y con el afán de superar la contraposición de los modelos, la educación según las humanidades no debería relegar las competencias tecnológicas o tecnocráticas, como las sistémicas e instrumentales, a pesar de que acentúe aquellas competencias, como las genéricas, que construyen dialógicamente un tipo de identidad socialmente deseable. No se puede aceptar que el objeto del reconocimiento consista sólo en promover competencias empresariales o mercantiles dejando de lado las competencias civiles o democráticas como la responsabilidad y participación social.

Así, un modelo educativo que promueva todo el potencial de las humanidades y una pedagogía dialógica puede asegurar correctas relaciones sociales de reconocimiento y promover una auténtica formación de la identidad, pues todos tienen la obligación y el derecho de desarrollar sus capacidades sociocognitivas, culturales y cívicas. Por consiguiente, ¿̇por qué no diseñar un modelo educativo holista de las competencias que apunten a formar la identidad y autonomía en clave 
intersubjetiva y que beneficie tanto al mercado con economía solidaria como a la sociedad democrática, plural y tolerante?

La objeción a la interpretación que subyace en el modelo educativo tecnocrático no sólo es porque evita formar en las capacidades ético-políticas y genera ciudadanos atomizados o porque afecta a las políticas educativas basada en las humanidades, sino también porque en su afán por promover sólo competencias instrumentales y sistémicas, termina alentando "un reconocimiento que discrimina positivamente", y homogeneiza la formación de las identidades en torno a la mercantilización y el consumismo. Por otro lado, si lo que importa a las políticas educativas inspiradas en las humanidades es el reconocimiento para una identidad asociada a la civilidad, deberán esforzarse por recrear el significado y sentido de sus asignaturas en cuanto a sus contenidos y estrategias pedagógicas, de modo que no desaparezcan, ni favorezcan indirectamente el posicionamiento absoluto del modelo tecnológico liberal.

Estos modelos educativos y sus respectivas políticas implican concepciones antropológicas y sociológicas específicas. En efecto, la interpretación tecnológica supone que cada individuo tiene un potencial cognitivo que merece desarrollar hasta hacerse competente, es decir, eficiente, en uno u otra profesión, pues todos deben desarrollar sus capacidades productivas para lograr sus eventuales proyectos empresariales; sin embargo, hay que considerar que tales individuos también tienen un potencial sociocultural, que las humanidades buscan desarrollar como potencialidad universal/particular del ser humano, ya que cualquiera puede definir su propia identidad sólo en relación a una comunidad cultural específica abierta a otros valores culturales que le pueden enriquecer.

Una crítica a la educación tecnológica o tecnocrática es que atenta no sólo contra la autodeterminación de una auténtica identidad (al excluir la comunidad), sino que también discrimina al imponer las competencias tecnológicas solo para el mercantilismo y el consumismo. Taylor diría que se trata de un modelo educativo "ciego a la civilidad y la democracia".

Así, el Estado democrático que respeta la autonomía universitaria, no niega el derecho a que las universidades privadas se comprometan a educar según el enfoque de las competencias que crean conveniente. Sin embargo, no se trata de un tema legal o político sino moral y ético, ya que los modelos educativos no son neutrales y además los estudiantes, cada vez más, necesitan afrontar razonablemente sus diferencias y vivir en democracia, a pesar de la percepción negativa que puedan tener de ella en cuanto a la solución de los graves problemas sociales que aún nos aquejan.

Esto plantea la pregunta de si se puede justificar un modelo que promueva sólo la supervivencia de una identidad individualista en contextos multiculturales, o si es mejor aquel modelo que forje la identidad abierta a la intersubjetividad, es decir, al reconocimiento del otro, y esto a pesar de que existe la tendencia a "menospreciar" las humanidades y las ciencias sociales en numerosas escuelas y facultades universitarias donde se impone una malla curricular con clara orientación a la instrumentalización y cosificación del ser humano, pues sólo se busca responder a las exigencias del mercado local y global. 
En todo caso, si los estudiantes desean libremente formar su identidad de modo atomizada e insolidaria, habría que dejárselo decidir a ellos; pero no sería aceptable la imposición política de un modelo educativo que exacerbe el individualismo y que sea ciego a la formación del reconocimiento de las diferencias culturales. En realidad, la cultura dominante del capitalismo tiende a reafirmar su hegemonía reproduciendo los diversos individualismos, incluso académicos, ante la indiferencia y complicidad del Estado.

Por ello, patrocinamos un modelo educativo integral e integrador que promueva el reconocimiento de las diferencias culturales en torno a objetivos comunitarios, en donde las competencias sociocognitivas se amplíen con las actitudinales, éticas y políticas. Eludir esta tarea implicaría no sólo negar el derecho y el deber moral de formar una identidad auténtica, sino también de renunciar a promover un auténtico reconocimiento, lo que traería consecuencias negativas en la construcción de la sociedad democrática. Y el criterio para establecer dicho modelo deberá ser siempre el interés de la sociedad, y no sólo del mercado, validado procedimentalmente mediante la deliberación y el diálogo democrático.

\section{CONCLUSIÓN}

De la tensión entre el modelo educativo tecnológico y el de las humanidades, surge la alternativa del modelo educativo holista de las competencias como una forma de promover un verdadero reconocimiento que ayude a formar ciudadanos autónomos y solidarios, capaces de someter a crítica las tradiciones, creencias y valores y revertir las persistentes desigualdades y exclusiones socioculturales. Este modelo debe responder a la necesidad de vincular correctamente la educación y el reconocimiento como elemento clave para la formación de una auténtica identidad personal y que reconozca las diferencias socioculturales en clave dialógica. El modelo tecnológico o tecnocrático no sólo promueve un falso reconocimiento o reconocimiento reducido, sino que tampoco favorece al desarrollo eco-sostenible de la sociedad, pues está influenciado por la ideología dominante y del afán de lucro y poder y, por lo mismo, no le interesa promover una sociedad incluyente y con igualdad de oportunidades para todos. Este modelo necesita desideologizarse y abrirse a las demandas urgentes de la sociedad respecto de un plan integral formativo que incluya no sólo las ciencias básicas, sino también las humanidades y las ciencias sociales como condición de posibilidad de una sociedad justa.

Las orientaciones y prácticas educativas de nuestro modelo pueden constituirse en fuente normativa para la validez y justificación de los modelos que siguen las numerosas escuelas y universidades privadas en nuestro entorno, los cuales deberían ampliar sus respectivos enfoques sobre las competencias, pues no pueden quedar subsumidos solo por las exigencias productivas del mercado local y global, ya que promueven una identidad individualista e intolerante que buscará imponerse por sobre la otra, y se afirmará sólo la libertad económica generándose identidades paralelas (Tubino 2015). Sin embargo, no podemos idealizar a las humanidades ni a las ciencias sociales, pues como hemos dicho éstas necesitan renovarse tanto en contenido como en estrategias pedagógicas deliberativas o dialógicas y abrirse al diálogo interdisciplinar para contribuir efectivamente no sólo al desarrollo sostenible de la sociedad, sino 
ante todo para contribuir a la formación de un correcto reconocimiento mutuo de las diferencias socioculturales y evitar que la dignidad e identidad del ser humano quede afectada o reducida.

\section{REFERENCIAS}

Delors, J. (1996) La educación encierra un tesoro. Informe a la Unesco de la Comisión Internacional sobre la educación para el siglo XXI. Paris: UNESCO.

Giusti, M. (2017) El paradigma del reconocimiento en la ética contemporánea. Un debate en curso. RELAER.

Habermas, J. (2009) "La lucha por el reconocimiento en el estado democrático de derecho". En Taylor, Ch. Multiculturalismo y política del reconocimiento. México: FCE.

Honneth, A. (1997) La lucha por el reconocimiento. Por una gramática moral de los conflictos sociales. Barcelona: Edición Crítica.

López Segrera, F. (2006) Escenarios mundiales de la educación superior. Análisis global y estudios de casos. Buenos Aires: CLACSO. Recuperado de: http://bvsde.org.ni/clacso/ publicaciones/Escenariosmundialesdel aEducacionSuperior.pdf

Morin, E. (1999) Los siete saberes necesarios para la educación del futuro. Paris: UNESCO.
Nussbaum, M. (2005) El cultivo de la humanidad. Una defensa clásica de la reforma en la educación liberal. Paidós: Barcelona.

Nussbaum, M. (2010) Sin fines de lucro. Por qué la democracia necesita de las humanidades. Madrid/Buenos Aires: Katz.

Organización Mundial del Comercio (OMC) (1995)_https://www.wto.org/ spanish/tratop s/serv s/finance s/ finance fiback_s.htm

Román, M. (2006) Aprender a aprender en la sociedad del conocimiento. Santiago de Chile: Editorial Conocimiento.

Taylor, Ch. (2009) Multiculturalismo y política del reconocimiento. México: FCE.

Tobón, S. (2013) Formación integral y competencias. Bogotá: Ecoe Ediciones.

Tubino, F. (2015) La interculturalidad en cuestión. Lima: Fondo Editorial PUCP.

UNESCO (1998) Declaración Mundial sobre la Educación Superior en el Siglo XXI. http:// www.unesco.org/education/educprog/ wche/declaration_spa.htm

Walzer. M. (2001) Las esferas de la justicia. Una defensa del pluralismo y la igualdad. México: FCE. 